\title{
Getting Research into Clinical Practice - Barriers and Solutions
}

\author{
J.E. Clarkson \\ University of Dundee, Dental Hospital and School, Dundee, UK
}

\author{
Key Words \\ Implementation $\cdot$ Practice $\cdot$ Primary care
}

\begin{abstract}
The success of current efforts towards evidence-based health services in many countries depends on efficient transfer of research findings to health practitioners. However, there is a lag in research being adopted. In part this is due to difficulties in interpreting or generalising research findings, in part to inertia, organisational structures and information. Clinical guidelines are usually cited as being the most effective product of evidence assessment and means of getting research into practice. The processes by which they are prepared and disseminated are discussed. Current clinical practice requires that health professionals adapt to changing systems and adopt new techniques. Therefore, in future, practice research to evaluate (a) clinical interventions and (b) dissemination and implementation strategies will become increasingly important. Recognised barriers to such research include lack of interest, lack of involvement, lack of time and lack of remuneration. High-quality research in dental primary care requires academics and dental service providers working in partnership on topics that are relevant both to clinicians and policy makers. Good project management, education and training are essen-
\end{abstract} tial.

Copyright $(2004$ S. Karger AG, Basel

\begin{tabular}{ll}
\hline KARGER & ( ) 2004 S. Karger AG, Basel \\
0008-6568/04/0383-0321\$21.00/0 \\
$\begin{array}{l}\text { Fax +4161306 12 34 } \\
\begin{array}{l}\text { E-Mail karger@karger.ch } \\
\text { www.karger.com }\end{array}\end{array}$ & $\begin{array}{l}\text { Accessible online at: } \\
\text { www.karger.com/cre }\end{array}$
\end{tabular}

Understanding factors that influence the implementation of research findings in clinical practice is perhaps one of the greatest challenges members of ORCA face. In this presentation, I will discuss issues concerned with getting research into clinical practice, both barriers and solutions. I will consider the existing information, state of the art, future perspectives and potential impact on practice. I should first like to remind you of the motivation to establish this organisation. The five founding members of ORCA were general dental practitioners who recognised the need to promote the dissemination of caries research in dental practice. The recommendation to ORCA in the 1970s for there to be inclusion of social and behavioural scientists recognised a need to understand behaviour change and that probably still holds true for today.

With regard to existing information, it is well recognised that the bulk of research evidence has not been generated in settings where most clinical care is provided. Academic or hospital-based research is more common than research in primary care and there is resistance to generalising research findings because of possible differences in the population groups and clinical environment. So there is a lag time in research being adopted; additional reasons for this include inertia, organisational structures, information overload and interpretation difficulties where there are incomplete or inconsistent results and/or conflict [NHS Centre for Reviews and Dissemination, 1999; McGlone et al., 2001]. Professional behaviour has

J.E. Clarkson

Dental Health Services Research Unit

The Mackenzie Building, Kirsty Semple Way

Dundee DD2 4BF (UK)

Tel. +44 1382 420060, Fax +44 1382 420051, E-Mail j.e.clarkson@dundee.ac.uk 
to change. The linear model that providing knowledge will change attitudes and therefore behaviour I believe to be too simplistic. However, access to appropriate knowledge is essential and clinical guidelines are usually cited as being the most effective product of evidence assessment and means of getting research into practice.

This brings me to the state of the art. I would like to discuss the most recent systematic reviews evaluating guideline dissemination and implementation and give an overview of the Cochrane Oral Health Group, as this is the resource most appropriate for dentistry. Guidelines are systematically developed statements to assist practitioner decisions and patient decisions about appropriate health care for specific clinical circumstances [Field and Lohr, 1990].

EPOC (Effective Practice and Organisation of Care) is one of the 50 review groups in the Cochrane Collaboration that undertake the development and maintenance of systematic reviews concerned with the effectiveness of practice and organisation of care. This group has recently completed an update of a previous systematic review evaluating the effectiveness of dissemination and implementation strategies for clinical guidelines. This update found education to be effective, which is in contrast to the original review and contains 235 studies, of which 110 (47\%) were cluster randomised controlled trials [Grimshaw et al., 2001, 2004]. Cluster trials represent best practice because they are considered to be the most appropriate methodology for implementation research: where the practice or practitioner is the unit of analysis and not the patient. The cluster trials contained 309 comparisons of different implementation strategies, the most common being reminders, education, audit and feedback. Audit and feedback involve practitioners taking part in an audit relevant to a guideline and reflecting on feedback; education includes dissemination of guidelines and related events; reminder systems are mechanisms that identify (flag up) patients with certain characteristics. The synthesised results of a change in practice, that is, implementation of the guideline, indicate a similar median size effect for audit and feedback (7\%, range 1-16\%) and education (8\%, range 4-17\%). The overall effect for reminders was not significant $(13 \%$, range -1 to $34 \%)$. The difference between the original and updated reviews indicates the importance of including contemporary evidence and maintaining systematic reviews.

Access to best evidence is important for patients, practitioners, guideline implementation groups and policy makers. Systematic reviews are considered the highest level of research evidence. The Cochrane Oral Health Group [http://www.cochrane-oral.man.ac.uk] was founded in 1994 and is considered to have the most comprehensive database of trial evidence in dentistry. In the most recent version of the Cochrane Library [Update Software, Issue 2 , 2003] using the research terms 'caries' or 'decay' retrieves 14 completed systematic reviews of randomised clinical trials and 26 protocols registered for ongoing systematic reviews. Also the Database of Abstracts of Reviews of Effectiveness (DARE) contains 24 items which are critically appraised - not any of which are Cochrane systematic reviews related to caries. In the trial register, there are over 16,000 entries concerned with oral health and 2,000 of these involve trials of interventions for caries management. The series of 4 systematic reviews evaluating the effectiveness of topical fluorides contains data from over 125 randomised clinical trials and 60,000 participants [Marinho et al., 2003a-d]. These reviews compared the effectiveness of fluoride toothpaste, gel, varnish and mouth rinses in relation to placebo and the summary statistics include preventive fractions and numbers needed to treat. The number needed to treat is the reciprocal of the risk or rate difference and can be interpreted as the number of patients needed to be treated for one to be cured.

In many countries, policy makers and service providers are exploring ways to make health services evidence based. The Cochrane Oral Health Group has recently collaborated with the Dental Health Services Research Unit and the Italian Cochrane Centre to supply information about evidence in dentistry to the Italian Government for future service planning. From this mapping exercise of trials in dentistry, comparing the characteristics of trials for caries with those of other trials in dentistry demonstrates that these are more likely to be with children and involve more participants. This finding reflects issues concerned with the conduct and cost of caries research.

There is a lack of clinical research evidence from general practice. I think that in the future the two important areas for practice research will be clinical interventions and the evaluation of dissemination and implementation strategies. Current clinical practice requires that health professionals adapt to changing systems and adopt new techniques. In terms of complexity of science, it would be akin to a complex adaptive system [Plsek and Greenhalgh, 2001]. This is defined as a collection of individual agents with freedom to act in ways that are not always totally predictable, and whose actions are interconnected so that one agent's actions change the context for other agents. In the past, we have trained dentists with a focus on competence, training them to repeat similar tasks in familiar 
environments. Perhaps that would have been sufficient 50 years ago, when amalgam was the main restorative material. However, today we should be training individuals to adapt to information which is becoming available and to deal with the increasingly broad ranging and large body of research evidence [Fraser and Greenhalgh, 2001].

An example of initiatives designed to support research in dental primary care is the Scottish consortium for development and education in dental primary care [Clarkson et al., 2000]. Its initiatives include higher training fellowships and the Scottish Dental Practice-Based Research Network which is housed in the Scottish School of Primary Care. Currently, the network has over 300 members. Support is given to take projects from initial ideas to grant proposals, while an online journal [www.tuith.co.uk] provides updates on research activity and access to clinical guidelines. We have found that general practitioners are keen to access research evidence and Tuith receives over 5,000 hits per month, with the most frequently used link being to guidelines. An example of how this has worked is in the development of what is referred to as the Hall technique. The sequence of events for this particular project was that a regional audit identified a dentist who was placing stainless steel crowns on deciduous teeth without prior removal of decay or local anaesthetic. In order to evaluate this technique further, a regional network was funded to conduct a pilot project [Evans et al., 2000]. One of the participating dentists is now lead investigator for a randomised controlled trial with joint government and industry funding which supports both her salary and her study for a PhD.

Research into the evaluation of implementation strategies in dentistry is sparse. We have experience of evaluating the effectiveness of audit and feedback compared to computer-aided learning strategies, for the dissemination of SIGN (Scottish Intercollegiate Guideline Network) Third Molar Guidelines [Bahrami et al., 2002]. The background to the development of these guidelines was the high cost of treatment and the high level of inappropriate treatment. The trial demonstrated the challenge of recruiting practitioners to participate in research: out of 565 approached, only 63 were recruited and only 51 took part in the final analysis. It raised the issue of whether a representative sample (of practitioners) is important for this kind of research, because the pre-intervention agreement with the guideline was high at $74 \%$. However, this might not be a problem of selection bias so much as a reflection of current practice, because national data of third molar extractions in Scotland peaked in the 1990s, with a sudden downturn in 1998.

Getting Research into Practice
Table 1. Summary of barriers and solutions

\begin{tabular}{ll}
\hline Barriers & Solutions \\
\hline $\begin{array}{l}\text { Lack of interest } \\
\text { Lack of involvement }\end{array}$ & $\begin{array}{l}\text { Research topics relevant to general practice } \\
\text { Invite practitioners to participate in taking } \\
\text { forward a research idea } \\
\text { Reduce practice time by } \\
\text { Coordinating research with efficient } \\
\text { management systems } \\
\text { Utilising routine data } \\
\text { Recruiting multiple practices/ } \\
\text { practitioners }\end{array}$ \\
Lack of remuneration & $\begin{array}{l}\text { Payment for time taken and reward of } \\
\text { continuing professional development }\end{array}$ \\
\hline
\end{tabular}

Recognised barriers to research in primary care include lack of interest, lack of involvement, lack of time and lack of remuneration. All of these issues present a challenge to the current demand for an increase in capability and capacity for research in primary care. In Scotland, with its high caries incidence, we have an ideal environment for trials for caries prevention. An example is a current study evaluating the effectiveness of implementation strategies based on remuneration and training in evidence-based health care. The outcome is clinical practice in accordance with SIGN guidelines on targeted caries prevention for 6- to 16-year-olds [Royal College of Physicians of Edinburgh, 2000]. Within this cluster randomised controlled trial, we will be evaluating 6 theories of behaviour change and measuring how closely theoretical constructs can predict professional behaviour. The reason for this is to find out not only whether our interventions work, but why. The result will inform future implementation strategies in dentistry. A particular challenge in conducting cluster trials in dentistry is our observation that the intra-class correlation coefficient of clinical treatment appears much higher for dental practice than for medical practice. The implication of this is that larger trials involving more practices and patients need to be conducted. There is an increasing amount of empirical research available to assist the design of such research, for example, a systematic review on questionnaire design [Edwards et al., 2002].

I believe that in order to increase the conduct of research in dental primary care, it must be of high quality; there need to be partnerships between academic units and service providers; the research should be relevant not only to clinicians but also to policy makers. Project management will determine the success or failure of a study, so 
investment is required, and the role of education and training in promoting research needs to be considered.

We are beginning to see the benefits of addressing barriers and the solutions require partnerships and resources (table 1).

I hope I have provided an overview of existing information, state of the art and future perspectives. So, what is the potential impact on clinical practice? The use of best evidence will enable high quality care to be provided and that will improve oral health. However, if this is to come about, there has to be a change in research practice, too.
Research needs to be relevant and researchers require a more sophisticated understanding of policy process. There needs to be collaboration to enable quality research and it is important that the results are generalisable. This presents a particular challenge when interventions are skill based as opposed to therapeutic or drug based. If ORCA is to take forward the vision of its founding members, then I think heed should be paid to the recommendation in the 1970s to include social and behavioural scientists. Understanding professional behaviour change will make a difference to getting research into practice.

\section{References}

Bahrami M, Bonetti D, Clarkson JE, et al: Effectiveness of different dissemination and implementation strategies for evidence-based guidelines for third molar problems in primary dental care. 7th Eur Forum Qual Improv Health Care, Edinburgh, 2002.

Clarkson JE, Murray M, Pitts NB, MacFarlane TW, Newton JP, Burke FJT, Bain CA, Ibbetson R, Rennie JS: Scottish consortium for development and education in dental primary care. Br Dent J 2000;189:222-223.

Edwards P, Roberts I, Clarke M, DiGuiseppi C, Pratap S, Wentz R, Kwan I: Increasing response rates to postal questionnaires: Systematic review. BMJ 2002;324:1-9.

Evans DJP, Southwick CAP, Foley JI, Innes NP, Pavitt SH, Hall N: The Hall technique: A pilot trial of a novel use of preformed metal crowns for managing carious primary teeth. 2000. Tuith Online: http://www.dundee.ac.uk/tuith/ Articles/rt03.htm

Field MJ, Lohr KN (eds): Clinical Practice Guidelines: Directions for a New Program. Washington, National Academy Press, 1990.
Fraser SW, Greenhalgh T: Coping with complexity: Education for capability. BMJ 2001;323:799803.

Grimshaw JM, Shirran L, Thoase R, et al: Changing provider behaviour: An overview of systematic reviews of interventions. Med Care 2001;39:II2-II45.

Grimshaw JM, Thomas RE, Maclennan G, et al: Effectiveness and efficiency of guideline dissemination and implementation strategies. Health Technol Assess 2004;8:1-84.

Marinho VCC, Higgins JPT, Logan S, Sheiham A: Fluoride toothpastes for preventing dental caries in children and adolescents (Cochrane Review); in: Cochrane Library, Issue 3, 2003a. Oxford, Update Software.

Marinho VCC, Higgins JPT, Logan S, Sheiham A: Fluoride gels for preventing dental caries in children and adolescents (Cochrane Review); in: Cochrane Library, Issue 3, 2003b. Oxford, Update Software.

Marinho VCC, Higgins JPT, Logan S, Sheiham A: Fluoride varnishes for preventing dental caries in children and adolescents (Cochrane Review); in: Cochrane Library, Issue 3, 2003c. Oxford, Update Software.
Marinho VCC, Higgins JPT, Logan S, Shieham A: Fluoride mouth rinses for preventing dental caries in children and adolescents (Cochrane Review); in: Cochrane Library, Issue 3, 2003d. Oxford, Update Software.

McGlone P, Watt R, Sheiham A: Evidence-based dentistry: An overview of the challenges in changing professional practice. Br Dent J 2001; 190:636-639.

NHS Centre for Reviews and Dissemination: Getting evidence into practice. Eff Health Care Bull 1999;5:1-16. www.york.ac.uk/inst/crd/ ehc51.pdf

Plsek PE, Greenhalgh T: The challenge of complexity in health care. BMJ 2001;323:625628.

Royal College of Physicians of Edinburgh: Preventing Dental Caries in Children at High Risk: Targeted Prevention of Dental Caries in the Permanent Teeth of 6- to 16-Year-Olds Presenting for Care. Edinburgh, Scottish Intercollegiate Guideline Network, 2000, No 47. 